\title{
A Practical Approach for Grid-connected Pico-hydro Systems using Conventional Photovoltaic Inverters
}

\author{
Vicente Leite ${ }^{1,2}$, José Couto ${ }^{1}$ \\ ${ }^{1}$ Polytechnic Institute of Bragança \\ Bragança, Portugal
}

\begin{abstract}
Pico-hydro power generation has a considerable untapped potential, able to contribute to the increased energy demand whilst ensuring a low environmental impact. The integration of these systems into microgrids is an emerging solution for the electrification of remote regions and also for selfsustainable power systems. The integration of cheap and wide spread technologies to interface small capacity hydro power systems with the grid has become essential in order to enable the exploitation of small rivers and shallows reservoirs resources among many other applications such as in water supply systems. This paper presents a design procedure to integrate pico-hydro generators into the grid using conventional and widespread photovoltaic inverters.
\end{abstract}

Index Terms-Distributed generation, pico-hydro turbines, photovoltaic inverters.

\section{INTRODUCTION}

Distributed generation (DG) is a new paradigm to produce in-site, highly reliable and secure electrical power, able to cope with the ever increasing global energy needs and climate change [1-3]. The integration of DG based on renewable resources into microgrids is an emerging solution for electrification of remote regions and for self-sustainable systems. Pico-hydro power systems are well established and likely the most cost effective way to provide electricity and are even more dispatchable than solar and wind systems. Thus, pico-hydro power systems play an important role in the crucial energy mix, provided that they are based on cheap, reliable and mature technologies to enable the widespread exploitation of small rivers and shallows reservoirs.

Pico-hydro power plants are very small-scale infrastructures designed to generate electric power under $5 \mathrm{~kW}$ [4] by converting the power available in flowing waters in rivers, canals and streams and they are quite different from classical hydroelectric power plants. Small-scale hydropower stations are usually run-of-river schemes with no or very small dams and reservoirs, therefore associated with low impacts on the hydrological regimes, on the aquatic or riparian ecosystems and on landscapes $[1,5,6]$. They are a well-known renewable energy source considered as an environmental friendly energy conversion option, since they do not interfere significantly with river flows and fit in well with the surroundings $[5,7,8]$.

\author{
Ângela Ferreira ${ }^{1,2}$, José Batista ${ }^{1}$ \\ ${ }^{2}$ CISE - Electromechatronic Systems Research Centre \\ Covilhã, Portugal
}

Pico-hydro power generation is considered as the most appropriate solution for electrification of rural, isolated communities and hilly and mountainous regions where it is very expensive to implement conventional transmission and distribution power systems $[9,10]$. In fact, they have been particularly useful in some countries such as India, Nepal, China, Iran, Peru, Brazil and Kenya [7, 11].

In Europe, according to European Commission [12], "a large proportion of the potential involves refurbishing existing sites and low-head/very low-head plants. In fact, in Europe small hydropower has a huge untapped potential which could allow it to make a more significant contribution to future energy needs. Therefore, one priority is to develop cheaper technologies for small-capacity and low-head applications, to enable the exploitation of smaller rivers and shallows reservoirs."

Usually, pico-hydro power plants are stand-alone systems, providing electricity for basic needs of a house or a small village, with a turbine driving a generator and a load controller to regulate the voltage and frequency [10]. In those systems, since the energy is directly used by final consumers, it is essential to provide an effective regulation of the output voltage and frequency to prevent harming their appliances [1]. In some cases this is made by speed regulation using complex and highinertia mechanical devices which adjusts the flow to the turbine to meet variations in power demand. In alternative, the turbine always runs at rated power and the speed is controlled by adjusting the electrical power output instead of the water power input. In these cases, a ballast load is switched on and off by an electronic load controller in order to balance the power input and the output $[1,4]$.

Some off-grid systems are based on a generator and a battery, with or without an off-grid inverter, depending on whether the loads are AC or DC $[13,14]$. When connected to a grid, conventional pico-hydro systems are designed to operate at constant speed at different heads in order to approximate the shaft speed as close as possible to the rated speed of the generator [13], to ensure the requirements above mentioned. Therefore, in order to improve the efficiency of those systems, hidro power system generators should work at variable speed [15]. 
Considering variability of heads and the seasonal water flow variation, and recent advances in low speed generators with offthe-shelf low power solutions for wind systems, pico-hydro systems can be applied beyond those conventional application domains. If additionally to low speed generators, an inverter based grid interface is used, other turbine technologies become viable [16]. However, such dedicated inverters for grid connection as proposed recently $[2,15,17,18]$ would turn into an expensive solution and are far way to be an off-the-shelf technology available on the market. Quite on the contrary, photovoltaic (PV) inverters in the range of $5 \mathrm{~kW}$ are a mature and reliable technology widely available. Taking advantage of this, and considering the limitations of conventional solutions, the application of standard PV inverters in grid connected picohydro turbines is investigated in this paper. Some compatibility tests were already achieved in New Zealand. They were prepared by the Smithies Technology Ltd. using the so called EcoInnovation Smart Drives permanent magnet generators together with PowerSpout pico-hydro turbines. These turbines are designed to behave electrically like PV strings, so that they interact effectively with conventional PV equipment, including grid connected inverters and charge controllers [19]. However, a complete description and investigation of a general approach is not available yet. For this purpose, a design procedure is presented for hydro generation systems based on pico-hydro turbines and wide-spread PV inverters.

\section{DESCRIPTION OF THE PRACTICAL APPROACH}

The proposed practical approach for grid-connected picohydro systems is illustrated in Fig. 1. It is similar to a typical low power wind system but instead of a wind inverter with a specific parametrized power curve, it uses a conventional PV inverter. This solution has some important advantages such as broad range of products (up to $5 \mathrm{~kW}$ ) and technological independence. Furthermore, these wide-spread PV inverters are very cost competitive and its installation is widely disseminated among small and medium enterprises.

By using a PV inverter for a grid-connected pico-hydro turbine, as presented in Fig. 1, the input voltage of the PV inverter is the rectified output voltage of the generator instead of a DC voltage provided by a PV string. The solution is very simple but in order to be reliable and safe, the integration of the inverter with the generator must be properly assured. Thus, it is necessary to understand very well the operating areas of both devices and combine them properly. In fact, the behavior of the generator is very different from the one of a PV string. However, under certain operating conditions in terms of voltage and power ranges, and considering the generator' dynamics, the solution can be reliable and efficient, benefiting from the advantages already mentioned.

\section{A. Operating areas of $P V$ inverter generator}

The operating area (and its limits) of a PV inverter when connected to a PV string is shown in Fig. 2(a). The operating area of the generator and its characteristics at different speeds are presented in Fig. 2(b). Fig. 2(a) also shows some typical I-V characteristics of a PV module/string for different solar irradiance levels. These I-V curves are described by three points in datasheets: open circuit, short circuit and maximum power point at the so-called Standard Test Conditions (STC). The corresponding parameters are: short-circuit current $\left(\mathrm{I}_{\mathrm{SC}}\right)$, open

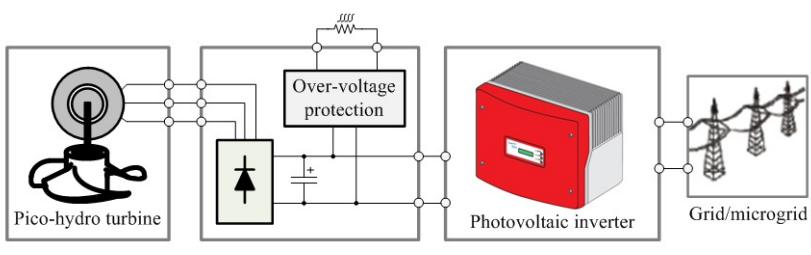

Figure 1. Practical approach for grid-connected pico-hydro systems.

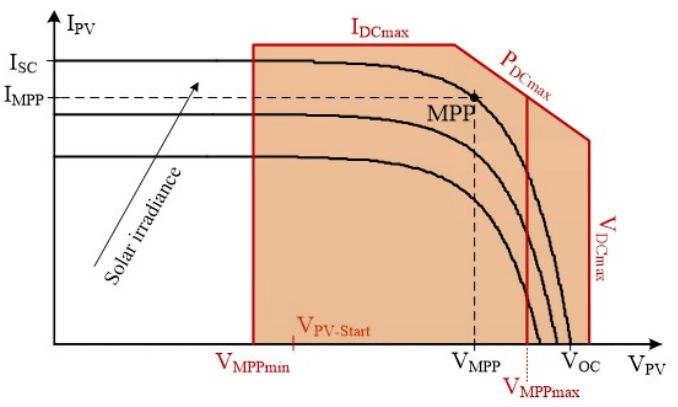

(a)

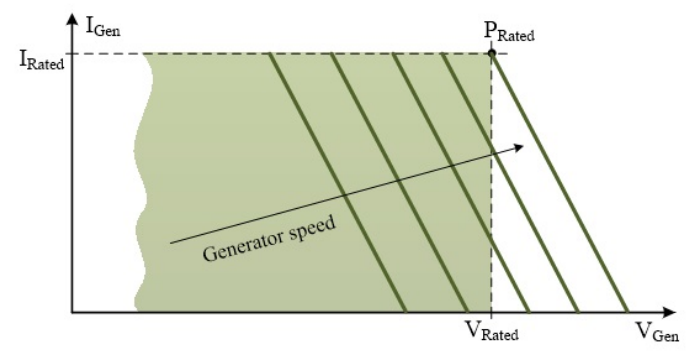

(b)

Figure 2. IV characteristics: (a) PV string and (b) generator.

circuit voltage $\left(\mathrm{V}_{\mathrm{OC}}\right)$, and voltage and current at the maximum power point (MPP), $\mathrm{V}_{\mathrm{MPP}}$ and $\mathrm{I}_{\mathrm{MPP}}$, respectively. In turn, the limits of the operating area of a PV inverter are given by manufacturers through a set of parameters: the maximum input current $\left(\mathrm{I}_{\mathrm{DC} \max }\right)$, the maximum input power $\left(\mathrm{P}_{\mathrm{DCmax}}\right)$, the maximum input voltage $\left(\mathrm{V}_{\mathrm{DCmax}}\right)$, the voltage range limits within which the inverter is able to track the MPP $\left(\mathrm{V}_{\mathrm{MPPmin}}\right.$ and $\mathrm{V}_{\mathrm{MPPmax}}$ ) and minimum voltage required before the inverter begins delivering power into the grid $\left(\mathrm{V}_{\mathrm{PV}-\text { Start }}\right)$ as shown in Fig. 2(a).

Both the above described parameter sets (for string and inverter) are used to size a PV system assuring the compatibility and suitable performance between the string of PV modules and the inverter as illustrated in Fig. 2(a). If a generator is to be connected to a conventional PV inverter, the operating point of the generator, i.e., the output DC voltage and current (after rectification), must be inside the safe operating area (SOA) of the inverter. This means that the I-V characteristics of a generator illustrated in Fig. 2(b) should be overlapped with the SOA shown in Fig. 2(a), as proposed in Fig. 3.

The I-V characteristics of a permanent magnet synchronous generator (PMSG) are presented in Fig. 2(b) and consists of a straight line for each specific speed. The abscissae correspond to the output DC voltage of the generator, when it runs at no load. The slope of the characteristics corresponds to the voltage drop in the internal impedance of the generator. This means that, for 
the same load/current, the voltage (and also the power) of a PMSG varies linearly with the speed. On the other hand, for a constant speed, the voltage decreases linearly with the load/current but the power increases because it is expected that, below rated conditions, the current increases much more than the voltage drop. Therefore, for a constant speed, when the PV inverter looks for the MPP at its input, by using a maximum power point tracking (MPPT) algorithm, it will maximize the current of the generator.

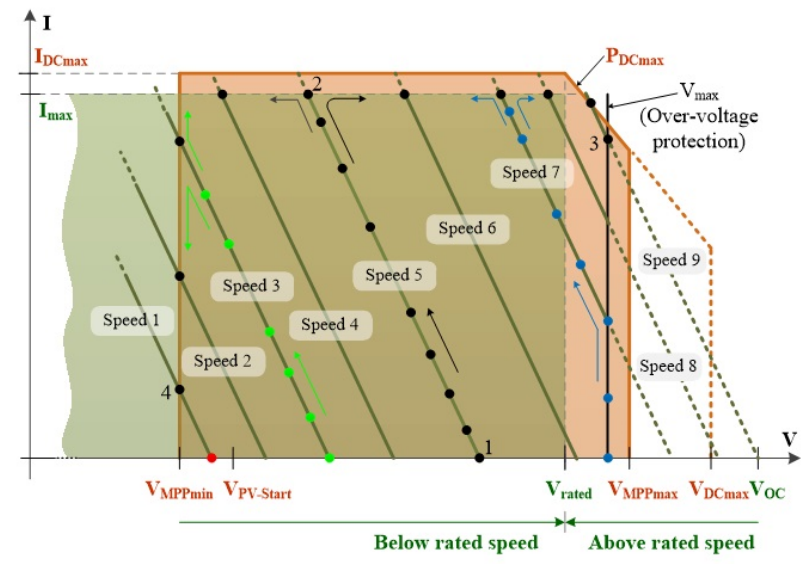

Figure 3. Overlapping of the operating areas of the generator and PV inverter and route of the inverter operating point with the speed variation.

Fig. 3 shows the locus of the operating point of the generator imposed by the MPPT algorithm for different initial speeds. For instance, if the initial speed is "Speed 5", the MPPT algorithm will start from point 1 and increases the current up to its maximum admissible, point 2 (black dots). The value of $\mathrm{I}_{\max }$ should be set near the rectified rated current of the generator and it may be limited by setting $\mathrm{I}_{\mathrm{DCmax}}=\mathrm{I}_{\text {Rated }}$ or through the internal impedance of the generator, from which the voltage variation superimposes to the current variation in finding the MPP. Thus, from this point, if the speed increases up to "Speed 9", the operating point will be set at point 3 , but if the generator slows down to "Speed 1", the operating point will be set in point 4. For the initial "Speed 3", the locus of the operating point is indicated by green-coloured dots. It will end in point 3 or 4 if the speed increases up to "Speed 9" or decreases till "Speed 1", respectively. However, if the initial speed is not high enough, as in case of "Speed 1", the inverter does not start delivering power into the grid because the generator DC voltage is lower than $\mathrm{V}_{\text {PV-Start }}$. When the initial speed is high, as in case of "Speed 7", the locus is indicated by blue-coloured dots. Then, the same happens as described for initial speeds 5 and 3 . In this case, an external circuit limits the voltage to $V_{\max }$ as will be explained in the next section.

\section{B. Design procedure}

The integration proposed in Fig. 1 for grid-connected picohydro systems is very simple but to be reliable and safe, this integration of a PV inverter with the generator must be properly assured. This requires a suitable design procedure as described hereinafter.

First, according to the European Efficiency Standard method, conventional PV inverters are designed to achieve their maximum efficiency at $50 \%$ of the rated power. On the other hand, hydro systems have higher equivalent operating hours than
PV applications. Considering this two facts, the rated power of the generator should be of the order of magnitude of $50 \%$ of the inverter maximum input power $\left(\mathrm{P}_{\mathrm{DCmax}}\right)$. As example, for a $\mathrm{PV}$ inverter with the efficiency presented in Fig. 4, the rated generator power should be as follows:

$$
0,4 \mathrm{P}_{\mathrm{DC} \max } \leq \mathrm{P}_{\mathrm{Gen}} \leq \mathrm{P}_{\mathrm{DC} \max }
$$

Second, for the speed range of a specific application, the rated output DC voltage of the generator (after rectification) must be within the input MPP range of the PV inverter.

Third, to ensure the compatibility between the inverter and the generator, the rated DC current of the generator must be equal or less than the maximum input current of the inverter $\left(\mathrm{I}_{\mathrm{DC} \max }\right)$. Therefore, the DC output voltage of the generator, for the maximum input power of the inverter, should be:

$$
\mathrm{V}_{\mathrm{DC}} \geq \mathrm{P}_{\mathrm{DC} \max } / \mathrm{I}_{\mathrm{DC} \max }
$$

If the rated DC voltage of the generator is higher than the value given by (2) the current will be lower and the PV inverter will be able to process the available power. Otherwise, it will limit the current at the input and therefore the power.

Fourth, in order to limit the voltage to $\mathrm{V}_{\mathrm{DCmax}}$, it is required an over-voltage protection circuit to prevent damaging the generator and the inverter. For instance, if the electric grid fails, the inverter must disconnect from the grid and the generator speed will increase. Since the voltage is proportional to the speed, an over-voltage protection is needed, as illustrated in Fig. 1, to divert power to an auxiliary power resistor in order to keep the input voltage of the inverter below $\mathrm{V}_{\mathrm{DCmax}}$.

Fifth, the no load output DC voltage of the generator for the initial speed must be higher than the value $\mathrm{V}_{\mathrm{PV} \text {-Start }}$ of the inverter.

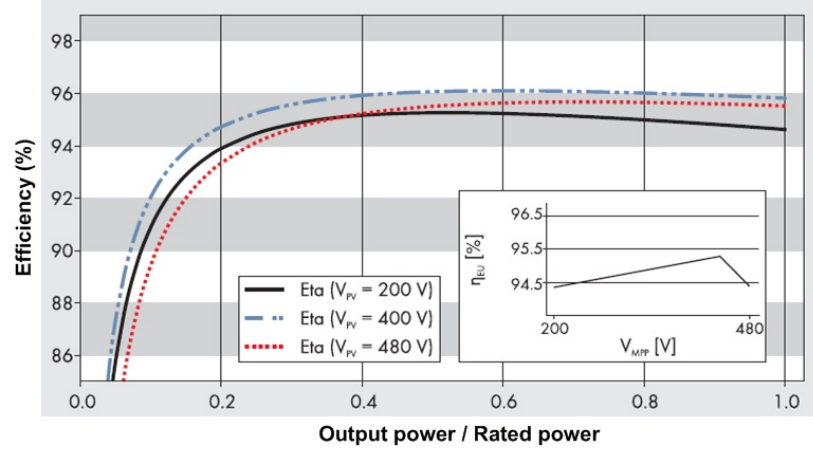

Figure 4. Efficiency curves of the PV inverter SB 2100TL.

Finally, the dynamics of the generator, in terms of acceleration and deceleration time constants, should be quite inferior to the ones of wind systems, e.g.. This is particularly important when the speed decreases since if it falls too quickly, the MPPT algorithm cannot follow the MPP and the voltage drops rapidly below $\mathrm{V}_{\text {MPPmin }}$ causing the inverter to stop. In fact, the MPPT algorithms of conventional PV inverters can have an execution period of the order 1 or $2 \mathrm{~s}$. This is a relatively long time constant for the power variation of a generator but fortunately, in hydro power systems, the dynamics is quite slow. 


\section{EXPERIMENTAL RESULTS}

To validate the proposed design procedure, an experimental platform emulating a typical power topology used in PV string inverters was used. Additionally, experimental tests with a standard PV inverter were also carried out, as described below.

Two 3-phase permanent magnet synchronous generators were used:

Generator 1 - Smart drive 60-2s-7p star;

Generator 2 - Smart drive 100-14s-1p star.

The technical data available from the supplier is presented in Table I. A $3 \mathrm{~kW}$ induction motor, controlled in speed by a frequency converter, was used as prime mover.

TABLE I. TeChNicAl Data of GeNERATORS

\begin{tabular}{ccccccc}
\cline { 2 - 7 } & & & \multicolumn{4}{c}{ at 1600 rpm } \\
\cline { 2 - 7 } & V/rpm & W/rpm & $\mathbf{V}_{\text {DC,oc }}(\mathbf{V})$ & $\mathbf{V}_{\text {DC }}(\mathbf{V})$ & $\mathbf{P}(\mathbf{W})$ & $\mathbf{I}(\mathbf{A})$ \\
\hline 60-2s-7p star & 0,15 & up to 1 & 240 & 144 & $<1600$ & $<11,1$ \\
\hline 100-14s-1p star & 0,27 & up to 1 & 432 & 259,2 & $<1600$ & $<6,2$ \\
\hline
\end{tabular}

\section{A. Tests with the experimental set-up}

The experimental platform which emulates a typical power topology used in PV string inverters, is based on a DC/DC boost converter and a single-phase voltage source inverter (VSI) as shown in Fig. 5.

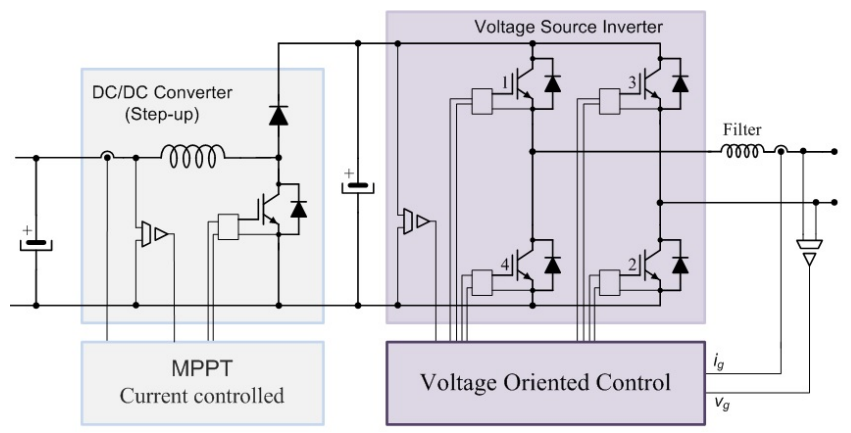

Figure 5. Typical power topology of PV string inverters used in the laboratory.

The experimental set-up is based on the MATLAB with Simulink and the dSPACE ACE kit based on the 1103 controller board. The boost converter and the VSI are implemented with the intelligent power module (IPM) PM75RLA120 from Powerex by suitable control of the seven IGBTs of this IPM. The boost converter is current controlled by means of a PI controller, providing maximum power point tracking by using the so-called Perturb \& Observe algorithm. The VSI controls the DC-Link voltage as well as the active and reactive power injected into the grid. The control scheme of the VSI is based on Voltage Oriented Control as described in [20,21].

This emulation platform was particularly useful to evaluate the performance of the overall system in dynamic conditions. For this purpose several tests were performed. Figures 6 to 8 present the I-V plots corresponding to the output DC current as a function of the output DC voltage of the generators as proposed in Fig. 3.
Fig. 6 presents the I-V plots with the generators starting from different speeds up to $1600 \mathrm{rpm}$. These tests were achieved with the following parameters: current step $(\Delta \mathrm{I})=0,2 \mathrm{~A}$, $\mathrm{V}_{\mathrm{DC} \text { min }}=120 \mathrm{~V}, \quad \mathrm{I}_{\mathrm{DC} \max }=8,6 \mathrm{~A}$ for generator 1 and $\mathrm{I}_{\mathrm{DCmax}}=4,8 \mathrm{~A}$ for generator 2 , MPPT period $\left(\mathrm{T}_{\mathrm{mppt}}\right)=0,2 \mathrm{~s}$ and acceleration time $\left(\mathrm{t}_{\mathrm{ace}}\right)=100 \mathrm{~s}$. These parameters, including the limit of $\mathrm{I}_{\mathrm{DCmax}}$, are imposed by software using the ControlDesk package from dSPACE. The plots show the locus of the operating point of the generators, starting from different initial speeds, provided that the no load DC voltage is higher than $\mathrm{V}_{\mathrm{PV}}$ Start for the starting speed.

Fig. 7 shows the plots with different tracking periods of the MPPT algorithm, with the same test conditions. Generator 1 runs from $900 \mathrm{rpm}$ and generator 2 runs from $600 \mathrm{rpm}$.

Fig. 8 presents the plots for different acceleration times. It should be noticed these acceleration times refer to the time required to accelerate from 0 to $1600 \mathrm{rpm}$ and not from the initial speed.

Fig. 9 shows additional tests in order to evaluate the effect of the generator (hydro system) dynamics. The tests with the generator 1 (left) consist of three runs from $1600 \mathrm{rpm}$ to $900 \mathrm{rpm}$ with different deceleration times. The tests with the generator 2 (right) consist of two runs 500-1600-500 rpm, with different acceleration / deceleration times.

Regarding steady state operation of the system with generator 1, obtained results at various speeds, are presented in Table II. The reported values are speed, N, output DC voltage, $\mathrm{V}_{\mathrm{DC}}$, current, $\mathrm{I}_{\mathrm{DC}}$, and power, $\mathrm{P}_{\mathrm{DC}}$, of the generator, and the power injected into the grid, $\mathrm{P}_{\mathrm{AC}}$.

TABLE II. STEAdy STATE OPERATION OF GENERATOR 1 WITH THE EXPERIMENTAL PLATFORM GRID INTERFACE

\begin{tabular}{ccccc}
\hline $\mathbf{N}(\mathbf{r p m})$ & $\mathbf{V}_{\mathbf{D C}}(\mathbf{V})$ & $\mathbf{I}_{\mathbf{D C}}(\mathbf{A})$ & $\mathbf{P}_{\mathbf{D C}}(\mathbf{W})$ & $\mathbf{P}_{\mathbf{A C}}(\mathbf{W})$ \\
\hline 1000 & 127,8 & 2,1 & 268,4 & 182 \\
\hline 1050 & 128 & 3,2 & 409,6 & 311 \\
\hline 1100 & 127,5 & 4,4 & 561,0 & 468 \\
\hline 1150 & 128 & 6 & 768,0 & 637 \\
\hline 1200 & 128 & 7 & 896,0 & 770 \\
\hline 1250 & 128,5 & 7,9 & 1015,2 & 866 \\
\hline 1300 & 126,9 & 8,6 & 1091,3 & 930 \\
\hline 1350 & 132,1 & 8,6 & 1136,1 & 980 \\
\hline 1400 & 137,4 & 8,6 & 1181,6 & 1020 \\
\hline 1450 & 142,6 & 8,6 & 1226,4 & 1070 \\
\hline 1500 & 147,9 & 8,6 & 1271,9 & 1110 \\
\hline 1550 & 153,2 & 8,6 & 1317,5 & 1170 \\
\hline 1600 & 158,2 & 8,6 & 1360,5 & 1200 \\
\hline
\end{tabular}

\section{B. Tests with a standard PV inverter}

The experimental set-up was very important to analyse and validate the proposed design procedure as described in the previous section but also tests with standard PV inverters were implemented. The results obtained with generator 1 and generator 2 are presented in Table III and Table IV, respectively. The values are the average of five measurements. 
The PV inverter used in this tests was the SB2100TL from SMA, with the following characteristics: $P_{\mathrm{DCmax}}=2200 \mathrm{~W}$, $\mathrm{I}_{\mathrm{DC} \max }=11 \mathrm{~A}, \quad \mathrm{~V}_{\mathrm{DC} \max }=600 \mathrm{~V}, \quad \mathrm{~V}_{\mathrm{MPP} \min }=125 \mathrm{~V}$, $\mathrm{V}_{\mathrm{MPPmax}}=480 \mathrm{~V}$, and the parameter $\mathrm{V}_{\mathrm{PV} \text {-Start }}$ set to $150 \mathrm{~V}$ (by default).

TABLE III. STEAdy STATE OPERATION OF GeNERATOR 1 WITH THE STANDARD PV INVERTER GRID INTERFACE

\begin{tabular}{ccccc}
\hline $\mathbf{N}(\mathbf{r p m})$ & $\mathbf{V}_{\mathbf{D C}}(\mathbf{V})$ & $\mathbf{I}_{\mathbf{D C}}(\mathbf{A})$ & $\mathbf{P}_{\mathbf{D C}}(\mathbf{W})$ & $\mathbf{P}_{\mathbf{A C}}(\mathbf{W})$ \\
\hline 1050 & 127,4 & 3,3 & 420,0 & 388 \\
\hline 1100 & 128,3 & 4,5 & 571,4 & 526 \\
\hline 1150 & 128,0 & 6,1 & 778,6 & 706 \\
\hline 1200 & 128,2 & 7,3 & 941,5 & 816 \\
\hline 1250 & 128,9 & 8,1 & 1049,8 & 938 \\
\hline 1300 & 129,2 & 9,0 & 1157,6 & 1022 \\
\hline 1350 & 128,8 & 9,7 & 1243,9 & 1086 \\
\hline 1400 & 128,0 & 10,3 & 1316,6 & 1150 \\
\hline 1450 & 129,4 & 10,6 & 1375,0 & 1194 \\
\hline 1500 & 132,9 & 10,8 & 1436,1 & 1244 \\
\hline 1550 & 138,3 & 10,7 & 1477,9 & 1290 \\
\hline 1600 & 140,8 & 10,8 & 1523,3 & 1338 \\
\hline & & & &
\end{tabular}

TABLE IV. STEAdY STATE OPERATION OF GENERATOR 2 WITH THE STANDARD PV INVERTER GRID INTERFACE

\begin{tabular}{ccccc}
\hline $\mathbf{N}(\mathbf{r p m})$ & $\mathbf{V}_{\mathbf{D C}}(\mathbf{V})$ & $\mathbf{I}_{\mathbf{D C}}(\mathbf{A})$ & $\mathbf{P}_{\mathbf{D C}}(\mathbf{W})$ & $\mathbf{P}_{\mathbf{A C}}(\mathbf{W})$ \\
\hline 600 & 127,6 & 2,0 & 256,2 & 216 \\
\hline 700 & 129,8 & 4,2 & 542,5 & 464 \\
\hline 800 & 129,1 & 5,5 & 707,4 & 618 \\
\hline 900 & 136,4 & 5,9 & 804,5 & 710 \\
\hline 1000 & 151,9 & 5,8 & 887,2 & 800 \\
\hline 1100 & 167,5 & 6,0 & 1011,9 & 884 \\
\hline 1200 & 184,3 & 6,0 & 1105,9 & 970 \\
\hline 1300 & 197,9 & 6,0 & 1195,6 & 1052 \\
\hline 1400 & 216,8 & 6,0 & 1296,3 & 1140 \\
\hline 1500 & 233,1 & 6,0 & 1389,4 & 1226 \\
\hline 1600 & 248,0 & 6,0 & 1488,1 & 1314 \\
\hline & & & &
\end{tabular}

\section{DISCUSSION}

From the results obtained and the analysis of the dynamic response presented in Fig. 6, 7 and 8, it can be seen that operating points of the generators are within the working area of the PV inverter, such as illustrated in Fig. 3. This is true provided that the MPPT is relatively fast, i.e., with a small tracking period (less than $1 \mathrm{~s}$ ) and the acceleration is moderate (with acceleration times of the order of tens of seconds). Obviously, the system dynamics will depend on the physical conditions of the practical applications. Nevertheless, as previously mentioned, hydro systems are typically characterized by a considerable inertia from which it is not expected high acceleration and deceleration time constants. However, they are faster than PV systems. Therefore, there may be two drawbacks. First, when the acceleration time is high, the over-voltage protection circuit must dissipate the excess power to an external resistance like in the wind systems. Second, when the deceleration is fast, the output DC voltage can decrease below $\mathrm{V}_{\mathrm{MPPmin}}$ and the PV inverter can stop its operation temporarily.
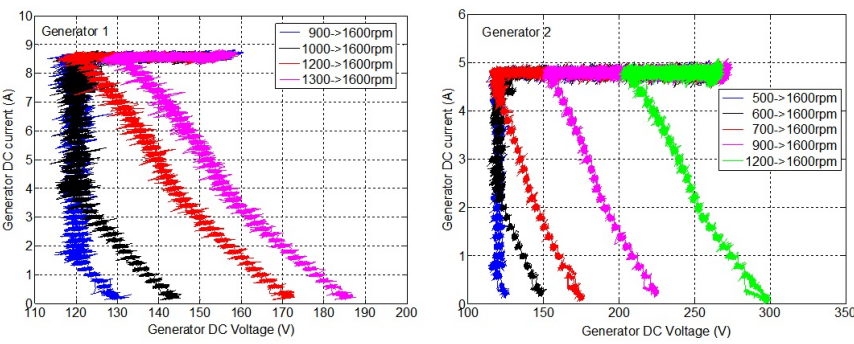

Figure 6. I-V plots with the generator 1 (left) and generator 2 (right) starting from different speeds up to $1600 \mathrm{rpm}$.
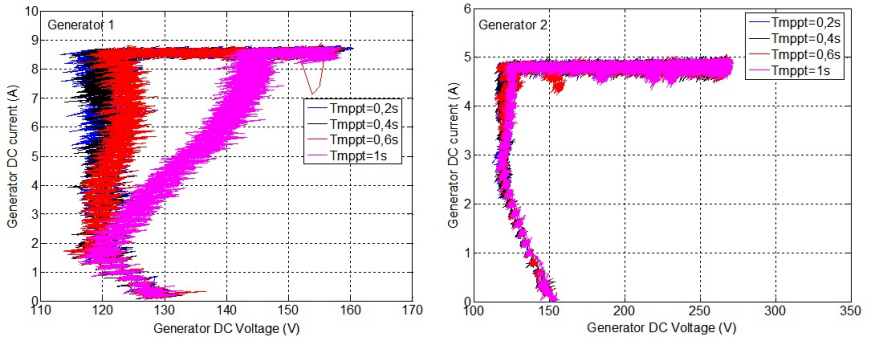

Figure 7. I-V plots with the generator 1 (left) and generator 2 (right) with different tracking periods of the MPPT algorithm.
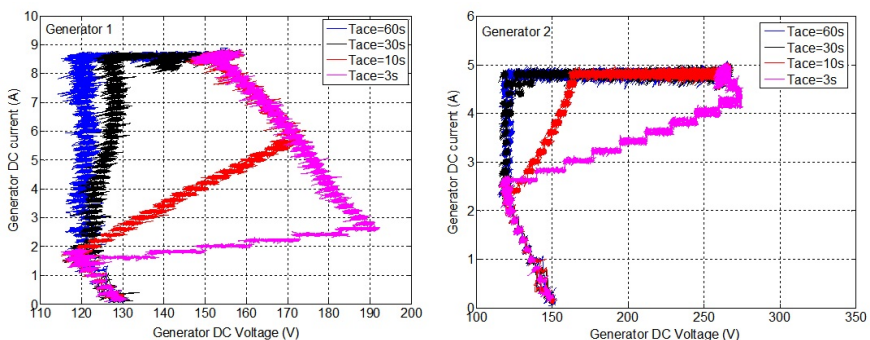

Figure 8. I-V plots with the generator 1 (left) and generator 2 (right) with different acceleration times.
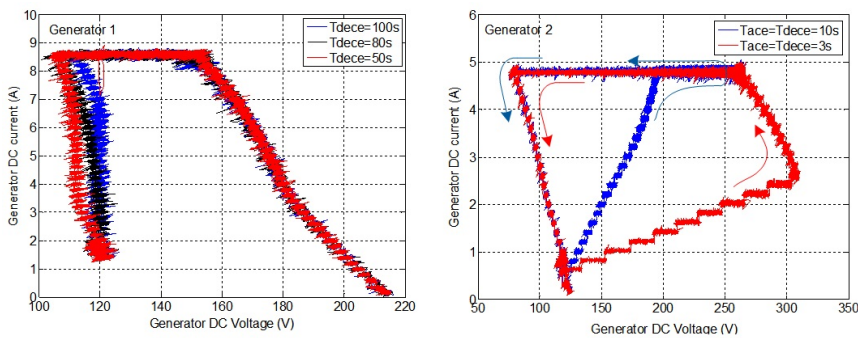

Figure 9. Evaluation of the generator (hydro system) dynamics: decelerations from $1600 \mathrm{rpm}$ to $900 \mathrm{rpm}$ with generator 1 (left) and two runs 500-1600$500 \mathrm{rpm}$ with generator 2 (right).

However, these are not critical problems for pico-hydro systems in terms of robustness and reliability of the solution proposed in this paper.

Usually, it is possible to change parameters of conventional $\mathrm{PV}$ inverters such as maximum output power, $\mathrm{V}_{\mathrm{PV}-\text { Start, }}$ and time delay before disconnecting from the electrical grid if the DC voltage drops below $\mathrm{V}_{\mathrm{PV} \text {-Start. Although these features can }}$ improve the robustness of the procedure presented above, the integration proposed in this paper outlines a simple task of plugand-play. However, in this case, it would be particularly important to be able to accelerate the MPPT algorithm by reducing its tracking period. 
Another additional concern with the experimental results is the hydro turbine emulation. The procedure has been tested using a speed control of the prime mover which does not allow an accurate model of the behavior of the pico-hydro power system in its full range. The speed reference imposes the output power and the open circuit voltage of the generator. In practice, when a hydro turbine delivers power to the generator, either the DC output voltage or current may vary. For the same power step, if the voltage increases, the current will decrease and viceversa. The upper and lower limits of the voltage are set by the overvoltage protection circuit and by the inverter, respectively. The current limit is defined by the inverter, setting $\mathrm{I}_{\mathrm{DCmax}}$, or through the MPPT algorithm as depicted by the experimental results shown in table IV.

Following this limitation, further work should address a more accurate turbine emulation, based on power control, and also a deep analysis of the MPPT performance. Additional tests with different sets of generators and commercial inverters should also be performed to investigate the robustness of the integration according to the design proposed procedure.

\section{CONCLUSION}

In this paper a practical approach for grid-connected picohydro systems using conventional photovoltaic (PV) inverters was proposed. The solution is based on a suitable integration of the generator and the PV inverter. For this purpose, a design procedure was presented to integrate pico-hydro generators into the grid using conventional PV inverters. Various experimental tests were carried out in the laboratory, using an emulation platform and a commercial PV inverter. The results obtained allow the validation of the proposed design procedure as well as the definition of the operating conditions, particularly in applications with a wide speed range.

The proposed integration of cheap and widespread PV inverters to interface small hydro power systems with the grid enables the exploitation of small rivers and shallows reservoirs resources among many other applications.

\section{REFERENCES}

[1] V. Leite, T. Figueiredo, T. Pinheiro, A. Ferreira and J. Batista, "Dealing with the Very Small: First Steps of a Picohydro Demonstration Project in an University Campus", in Proc. International Conference on Renewable Energies and Power Quality (ICREPQ'12), Santiago de Compostela, Spain, 2012.

[2] M. Molina and M. Pacas, "Improved Power Conditioning System of Microhydro Power Plant for Distributed Generation Applications", in Proc. International Conference on Industrial Technology, ICIT 2010, Vi a del Mar, 2010, pp. 1733-1738.

[3] J. M. Guerrero, et al., "Distributed Generation: Toward a New Energy Paradigm", IEEE Industrial Electronics Magazine, vol. 4, (1) pp. 52-64, March 2010.

[4] O. Paish, "Small Hydro Power: Technology and Current Status", Renewable and Sustainable Energy Reviews, vol. 6, (6) pp. 537-556, 2002.
[5] European Commission. (-, Access Date: September, 2015). Hydropower. Available:

http://ec.europa.eu/research/energy/eu/index_en.cfm?pg=researchhydropower

[6] European Commission, "A Guide to Environmental Impact Assessment of Small Hydropower Plants", Directorate-General for Energy and Transport, Brussels, 2000, p. 110.

[7] S. Khurana and A. Kumar, "Small Hydro Power - A review", International Journal of Engineering, Science and Metallurgy, vol. 1, (2) pp. 278-282, 2011.

[8] B. A. Nasir, "Design of Micro - Hydro - Electric Power Station", International Journal of Engineering and Advanced Technology, vol. 2, (5) pp. 39-47, June 2013.

[9] A. Desai, I. Mukhopadhyay and A. Ray, "Theoretical Analysis of a Picohydro Power System for Energy Generation in Rural or Isolated Area", in Proc. IEEE PES Asia-Pacific Power and Energy Engineering Conference, APPEEC 2014, Brisbane, 2014, pp. 1-4.

[10] S. J. Williamson, A. Griffo, B. H. Stark and J. D. Booker, "Control of Parallel Single-Phase Inverters in a Low-Head Pico-Hydro Off-Grid Network", in Proc. 39th Annual Conference of the IEEE Industrial Electronics Society, IECON 2013, 2013, pp. 1571-1576.

[11] D. A. Howey, "Axial Flux Permanent Magnet Generators for PicoHydropower", in Proc. EWB-UK Research Conference, 2009.

[12] European Commission. (-, Access Date: September, 2015). Hydro Energy, Technical background. Available: http://ec.europa.eu/research/energy/eu/index_en.cfm?pg=researchhydropower

[13] A. M. A. Haidar, M. F.M. Senan, A. Noman and T. Radman, "Utilization of Pico Hydro Generation in Domestic and Commercial Loads", Renewable and Sustainable Energy Reviews, vol. 16, (1) pp. 518-524, Jan. 2012.

[14] G. Yadav and A. K. Chauhan, "Design and Development of Pico Micro Hydro System by Using House Hold Water Supply", International Journal of Research in Engineering and Technology, vol. 3, (10) pp. 114119, June 2014

[15] W. Mazgaj, Z. Szular, T. Węgiel and T. Sobczyk, "Small Hydropower Plant with variable speed PM generator", Przeglad Elektrotechniczny, vol. 87, (5) pp. 282-287, 2011.

[16] S. J. Williamson, B. H. Stark and J. D. Booker, "Low Head Pico Hydro Turbine Selection using a Multi-Criteria Analysis", Renewable Energy, vol. 61, pp. 43-50, Jan. 2014

[17] A. Roque, D. M. Sousa, C. Casimiro and E. Margato, "Technical and Economic Analysis of a Microhydro Plant - a Case Study", in Proc. 7th International Conference on the European Energy Market, EEM 2010, 2010, pp. 1-6.

[18] U. C. Rathore and S. Singh, "Power Quality Control of SEIG based Isolated Pico Hydro Power Plant Feeding Non-Linear Load", in Proc. 6th India International Conference on Power Electronics, IICPE 2014, 2014, pp. 1-5.

[19] Andrew Smithies, "PowerSpout GE and ME Design for Compatibility with Inverters and MPPT Charge Controllers", Available: http://powerspout.com/assets/Published/public/PLT/PLTCompatibility/2011-01-PowerSpout-PV-compatibility-3-Nov-2011.pdf, Nov., 2011, p. 28.

[20] V. Leite, A. P. Ferreira and J. Batista, "Bidirectional Vehicle-to-Grid Interface under a Microgrid Project", in Proc. 15th IEEE Workshop on Control and Modeling for Power Electronics, COMPEL 2014, Santandair, Spain, 2014.

[21] S. Samerchur, S. Premrudeepreechacharn, Y. Kumsuwun and K. Higuchi, "Power Control of Single-Phase Voltage Source Inverter for GridConnected Photovoltaic Systems", in Proc. Power Systems Conference and Exposition (PSCE), IEEE/PES, 2011, pp. 1-6. 